\title{
Synthesis of Combretastatin A-4 Analogs with Antitumoral Properties
}

\author{
Natércia M. M. Bezerra, ${ }^{{ }_{1}}$ Gardênia C. G. Militão, ${ }^{2}$ Terezinha G. da Silva, ${ }^{2}$ \\ Paulo H. Menezes ${ }^{1}$ and Roberta A. Oliveira ${ }^{1}$ \\ 'Departamento de Química Fundamental, CCEN, UFPE, 50670-901, Recife-PE \\ ${ }^{2}$ Laboratório de Bioensaios para Pesquisa de Fármacos, Departamento de Antibióticos, UFPE, Recife-PE \\ *naterciammb@yahoo.com.br
}

Keywords: combretastatin A-4, potassium aryltrifluoroborates, vinyl tellurides

\section{INTRODUCTION}

Combretastatin A-4 (CA-4) (Figure 1), a natural Zstilbene isolated from the South African willow Combretum caffrum, has been found to strongly inhibit the tubulin assembly by binding to the colchicine site and to be a cytotoxic agent against a wide variety of cell lines, including multidrugresistant lines. $^{1}$

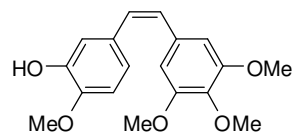

Figure 1: Combretastatin A-4

The structural simplicity of CA-4 combined with its excellent antitumor and antivascular activities encouraged the scientific community to synthesize numerous analogs. From these structure-activity relationship (SAR) investigations, it has been established that the cis-orientation of the two aryl rings is crucial for the activity of CA-4 as well as the trimethoxyaryl unit, whereas, the hydroxyl group on the 3 '-position is not essential.

Consequently, the synthesis of CA-4 analogs for further studies of their biological activities is of the great interest.

\section{RESULTS AND DISCUSSION}

The strategy to assembly the Z-double bond of CA-4 analogs was initially based on the use of the hydrotelluration reaction (Scheme 1).

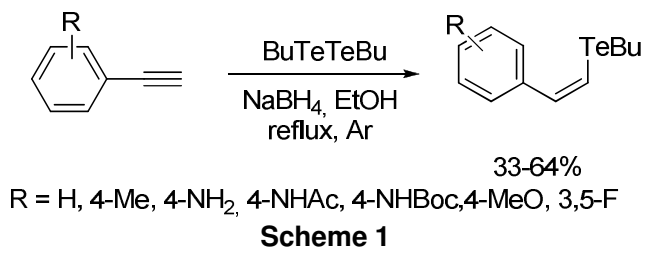

The desired tellurides were obtained in good to moderate yields, with exclusive $Z$ stereochemistry in all cases.

These compounds were then submitted to a Suzuki cross-coupling reaction with potassium aryltrifluoroborates $^{2}$ to give the desired stilbenes in good to moderate yields, being one feature of the method the tolerance of functional groups in both substrates (Scheme 2).

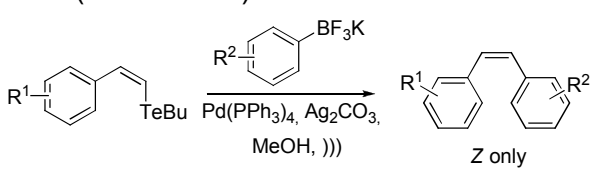

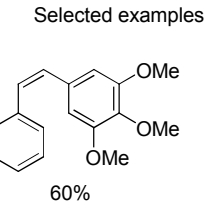

A1

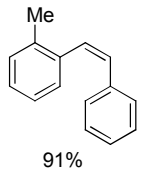

A2

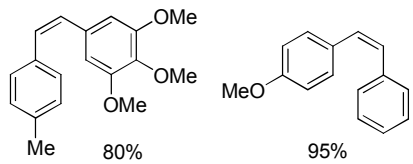

A3

A4
Scheme 2

In vitro antiproliferative activity of the synthesized stilbenes was determined against different cell lines. The A3 analog showed high citotoxicity against HL60 cells (leukemia) with a $\mathrm{IC}_{50}$ of $0.2 \mu \mathrm{g} / \mathrm{mL}$.

\section{CONCLUSION}

In summary, several functionalized stilbenes were synthesized in good yields. These compounds showed good antiproliferative activities agains tumor cell lines. The hydrotelluration reaction was used to assembly the $Z$ double and further cross-coupling reaction with potassium aryltrifluoroborates gave the desired analogs in a short synthetic pathway.

\section{ACKNOWLEDGEMENTS}

The authors gratefully acknowledge CNPq, CAPES, FACEPE and INCT-INAMI for the financial support.

\section{REFERENCES}

${ }^{1}$ Pettit, G. R.; Singh, S. G.; Boyd, M. R.; Hamel, E.; Pettit, R. K.; Schmidt, J. M.; Hogan, F. J. Med. Chem. 1995, 38,1666.

${ }^{2}$ Cella, R.; Stefani, H. A. Tetrahedron 2006, 62, 5656. 